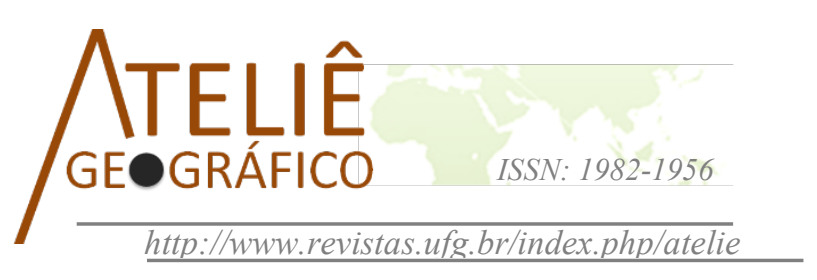

\title{
Limites e possibilidades das temáticas fisico-naturais na Base Nacional Curricular Comum: analisando os anos finais do ensino fundamental
}

\author{
Limits and possibilities of the physical-natural themes in the \\ National Curricular Common Base: analyzing the final \\ years of the Secondary School
}

\section{Limites et possibilités des thèmes de la nature dans la Base \\ Nationale Commune de Programme Scolaire (BNCC, Brésil): en examinant les années finales du collège.}

\author{
Anniele Freitas \\ Universidade Estadual de Campinas \\ anniesfreitas@gmail.com \\ Thiago Manhães Cabral \\ Universidade Estadual de Campinas \\ thiagomanhaescabral@gmail.com
}

\begin{abstract}
Resumo
O objetivo do trabalho é compreender a operacionalização dos modos de raciocínio (JO e BEDNARZ, 2009) e habilidades de pensamento (ANDERSON e KRATHWOHL, 2001) na produção dos conceitos espaciais ligados às temáticas físico-naturais, considerando as habilidades previstas na BNCC para os anos finais do ensino fundamental. Tais análises permitiram concluir que as temáticas físiconaturais privilegiam níveis de compreensão e processamento no campo das operações de raciocínio, bem como a exploração de conceitos espaciais complexos. Ao final, verifica-se a necessidade de resgatar a observação como habilidade primária de produção do conhecimento geográfico, de modo a resgatar a ideia de situação geográfica na direção da produção de sentidos significativos para as temáticas físiconaturais em múltiplas realidades escolares.
\end{abstract}

Palavras-Chave: raciocínio geográfico; ensino de geografia; currículo; ensino fundamental II

\section{Resumé}

L'objectif de ce travail est de comprendre le fonctionnement des modes de raisonnement (JO ET BEDNARZ, 2009) et capacités de la pensée (ANDERSON et 
KRATHWOHL, 2001) sur la production de concepts spaciaux associés aux thèmes de la nature, considérant les capacités prévues dans la BNCC pour le collège. Ces analyses permettent de conclure que les thèmes de la nature privilégient les niveaux de compréhension et traitement pour les opérations de raisonnement, ainsi que l'exploitation de concepts spatiaux complexes. À la fin, nous avons vérifié la nécessité de récupérer l'idée de situation géographique sur la direction de la production de sens significatifs pour les thèmes de la nature pour multiples réalités scolaires.

Mots-clés: raisonnement geographique; enseignement de la géographie, programme scolaire; collège

\begin{abstract}
The objective of this work is to understand the operation of modes of reasoning (JO and BEDNARZ, 2009) and thinking skills (ANDERSON and KRATHWOHL, 2001) in the production of spatial concepts related to physical-natural themes, considering the BNCC years of elementary school. These analyzes allowed to conclude that the physical-natural subjects are privileged levels of understanding and processing in the field of reasoning operations, as well as the exploration of complex spatial concepts. At the end, it is necessary to rescue observation as the primary ability to produce geographic knowledge, to rescue the idea of the geographical situation in the direction of the production of significant meanings for the physical-natural themes in multiple school realities.
\end{abstract}

Keywords: geographic thinking; geography teaching; curriculum; elementary school II

\title{
Introdução
}

$\mathrm{Na}$ área da Educação em Geografia, diversas pesquisas têm se dedicado à compreensão dos elementos cognitivos que perpassam as relações de ensinoaprendizagem, a construção de instrumentos avaliativos, bem como a elaboração das orientações curriculares. Trabalhos como o de Duarte (2016), Castellar (2017) e Roque Ascenção e Valadão (2017) direcionam esforços para a discussão das operações cognitivas que estão inter-relacionadas às específicas habilidades previstas para a Geografia enquanto disciplina escolar, ao passo que lançam mão de princípios como o raciocínio geográfico (CAVALCANTI, 2012), pensamento espacial (CASTELLAR, 2016), raciocínio espacial geográfico (ROQUE ASCENÇÃO E VALADÃO, 2017) e pensamento geoespacial (DUARTE, 2016). Dialogando com estas produções, este trabalho situa-se no campo da discussão curricular à medida que focaliza as habilidades previstas no texto da Base Nacional Comum Curricular para os anos finais do Ensino Fundamental, no tocante ao tratamento conceitual das temáticas físico-naturais. Nosso objetivo geral é compreender a operacionalização dos modos de raciocínio (JO e BEDNARZ, 2009) e habilidades de pensamento (ANDERSON e KRATHWOHL, 2001) na produção dos conceitos espaciais ligados às temáticas físico-naturais, considerando as habilidades previstas na BNCC para os anos finais do Ensino Fundamental (EF).

Para desenvolver este objetivo, será necessário um percurso de três etapas. A primeira será listar habilidades previstas na BNCC em termos das temáticas físiconaturais, contextualizando-as aos princípios do raciocínio geográfico apresentados no referido documento para os anos finais do EF. A segunda será interpretar, nas 
orientações curriculares para estas etapas de ensino, as associações previstas entre modos de raciocínio e habilidades de pensamento e o desenvolvimento dos conceitos espaciais ligados às temáticas físico-naturais. Por fim, a terceira e última etapa do trabalho visa avaliar o nível de complexidade conceitual explorado na habilidades previstas na BNCC, no tocante das temáticas físico-naturais. Toma-se tais etapas como os objetivos específicos do trabalho, que se articulam com os procedimentos metodológicos a seguir apresentados.

\section{Metodologia}

\section{Discussão Teórica}

Recentemente provocados pela chamada "a base é a base, e o currículo o que é?", título de um recente trabalho de Macedo (2018), iniciamos este trabalho assumindo um posicionamento acerca da ideia de currículo, no sentido de considerar a BNCC como um documento curricular que está para além de uma compilação de conteúdos, conceitos e habilidades organizadas em tornos das disciplinas escolares. Para Macedo (2016, pág 48) currículos de base nacional "[...] preenchem os sentidos de uma educação de qualidade ao mesmo tempo em que são significadas nas lutas políticas pela significação”, e seu argumento desvela-se na defesa de que a atual base reforça o papel de controle e da prescrição do conhecimento e das capacidades do fazer, negando mais uma vez que a "imprevisibilidade" da escola seja o espaçotempo de produção curricular. Assumimos que a noção de currículo compreendida em nossas pesquisas está em torno da forma de pensálo como uma produção cultural e discursiva que está inserida numa disputa pela produção do seu significado. Assim, este trabalho não pretende expor uma disputa em torno da produção de significações e de sua legitimação, mas sim pensar em como as teorias da aprendizagem podem se constituir como ponto nodal (LACLAU, 2011) de compreensão e debate sobre as teorizações de currículo no campo do ensino da Geografia.

Neste contexto, temos acompanhado o debate em torno das discussões sobre o pensamento espacial. Tal perspectiva é encontrada como uma das unidades temáticas nas séries finais do ensino fundamental para a Geografia. Assim, a unidade Formas de representação e pensamento espacial (BRASIL, 2017) registra conteúdos e ações didáticas relativas às formas representacionais cartográficas correlacionadas aos objetos de conhecimento geográfico. Nesse movimento, recorremos à uma breve revisão bibliográfica de modo que compreendêssemos o entendimento em torno da ideia de pensamento espacial.

Castellar (2017, p. 210) têm defendido que o pensamento espacial pode ser compreendido como uma "categoria geográfica importante para ler mapas e interpretar situações do cotidiano", corroborando com o argumento de que situações cotidianas podem ser interpretadas geograficamente através de situações-problema mediadas pela linguagem cartográfica. Duarte (2016) aprofunda esse debate em sua tese, onde defende a prerrogativa do pensamento geoespacial, de modo que se alcance a educação geográfica baseada na consciência da espacialidade das coisas 
(CAVALCANTI, 2012). Mesmo que os conceitos/conteúdos não tenham origem no pensamento espacial, seus fenômenos associados requerem um pensamento geoespacial. O debate proposto por Castellar (2017) e Duarte (2016) tomam como base o Spatial Thinking, um campo de pesquisas norte-americano que preocupa-se em aprofundar o conhecimento em torno da aprendizagem espacial na dimensão cotidiana, envolvendo processos de raciocínio segundo a neurociência (GERSMEHL e GERSMEHL, 2007).

Roque Ascenção e Valadão $(2017 ; 2014)$, em publicação preocupada com a construção de conhecimento de professores, recorrem às teorias cognitivas, como o Pedagogical Content Knowledge (SHULMAN, 1986) e os Cognitive Domains (BLOOM, 1956), de forma que o raciocínio espacial geográfico esteja inerente ao trabalho do professor, assegurado por operações de construção conceitual. Os conceitos e categorias da Geografia são o caminho metodológico para interpretação de questões de ordem geográfica (ROQUE ASCENÇÃO e VALADÃO, 2017, p.11) defendidas pelos autores como a espacialidade dos fenômenos.

Distante de manter uma exegese acerca das concepções e interpretações defendidas pelos autores supracitados, as referidas leituras destacadas acima têm nos orientado a pensar outras formas de exprimir o raciocínio geográfico, sem descartar seus posicionamentos, mas tentando coadunar a contribuição dos diversos pontos de vista apresentados nos mais variados meios de discussão.

Nesse movimento, uma preocupação é central nos apontamentos e interpretações produzidas neste trabalho: a construção de conhecimento pelo aluno por meio de conceitos da Geografia e operações de raciocínio que os envolvam. Partindo desse princípio, lançamos um olhar para o texto curricular da Base Nacional Comum Curricular, especificamente para as habilidades previstas para os anos finais do Ensino Fundamental, de modo a caracterizar os conceitos da Geografia Física por níveis de complexidade e em suas relações com as operações de raciocínio.

Nesse contexto, busca-se neste trabalho a aproximação entre dois aportes teóricos debruçados sobre a sistematização de operações de raciocínio no campo da aprendizagem: a taxonomia revisada de Bloom, apresentada por Anderson e Krathwohl (2001) e a Taxonomia do Pensamento Espacial, segundo Jo e Bednarz (2009). Em tal contexto, obras como a de Duarte (2016), Castellar (2016) e Roque Ascenção e Valadão (2017) são algumas daquelas debruçadas ora sobre a discussão desses autores em suas especificidades, ora nas associações possíveis de serem realizadas a partir de novas questões nos campos da cognição e aprendizagem em Geografia Escolar. Embora estejam, cada uma, situadas em temporalidades e contextos específicos, ambas têm em comum proposições que direcionam esforços para a compreensão da aprendizagem em níveis - ou momentos - de apreensão e complexidade.

Apesar de estar associada, em muitas discussões no cenário educacional brasileiro contemporâneo, ao pensamento de cunho tecnicista fixado em objetivos educacionais e avaliativos (ROQUE ASCENÇÃO e VALADÃO, 2017), a teoria de Bloom ainda é uma ferramenta útil às análises dedicadas a compreender os níveis de 
complexidade ou de apreensão conceitual envolvidos nas relações de ensinoaprendizagem. Nesse movimento, voltamos nossas atenções, neste trabalho, para a taxonomia do domínio cognitivo de Bloom, que, segundo Lopes e Macedo (2011, p. 52), “é um modelo analítico que propõe a classificação de todos os objetivos cognitivos em seis níveis: conhecimento (de fatos e conceitos), compreensão, aplicação, síntese e avaliação". Debruçados na revisão dos domínios cognitivos de Bloom à luz de novas questões advindas principalmente do campo da neurociência em educação, Lorin Anderson e David Krathwohl (2001) propõem uma reestruturação da taxonomia, no sentido de agrupar, em meio aos três níveis de processo mental - conhecimento, compreensão e apropriação - seis categorias: recordar, compreender, aplicar, analisar, avaliar e criar (Quadro 01).

Quadro 01: Taxonomia dos domínios cognitivos reorganizada.

\begin{tabular}{|c|c|c|c|c|c|c|c|c|c|c|}
\hline \multicolumn{11}{|c|}{ Processos Mentais } \\
\hline \multicolumn{3}{|c|}{ Conhecimento } & \multicolumn{4}{|c|}{ Compreensão } & \multicolumn{4}{|c|}{ Apropriação } \\
\hline 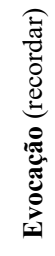 & & 苞 & 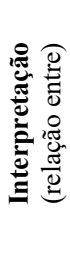 & : & & 胥 & 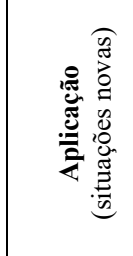 & 苋 & 苞 & 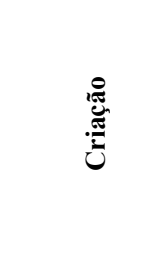 \\
\hline \multicolumn{3}{|c|}{$\begin{array}{c}\text { Reconhecer e } \\
\text { trazer à } \\
\text { memória } \\
\text { informações } \\
\text { relevantes; } \\
\text { memória de } \\
\text { longo prazo. }\end{array}$} & \multicolumn{3}{|c|}{$\begin{array}{l}\text { Construir significado } \\
\text { a partir de materiais } \\
\text { de leitura ou de } \\
\text { explicações. }\end{array}$} & & $\begin{array}{l}\text { Aplicação } \\
\text { de um } \\
\text { processo } \\
\text { apreendido; } \\
\text { situação } \\
\text { familiar ou } \\
\text { nova. }\end{array}$ & $\begin{array}{c}\text { Decomposição } \\
\text { do } \\
\text { conhecimento } \\
\text { em suas } \\
\text { partes, } \\
\text { buscando } \\
\text { identificar } \\
\text { como tais } \\
\text { partes se } \\
\text { relacionam } \\
\text { com a } \\
\text { estrutura } \\
\text { global. }\end{array}$ & $\begin{array}{c}\text { Comparar e } \\
\text { discriminar } \\
\text { ideias; dar } \\
\text { valor a } \\
\text { apresentação de } \\
\text { teoria; escolher } \\
\text { teorias } \\
\text { baseando-se } \\
\text { fundamentados; } \\
\text { verificar o } \\
\text { valor da } \\
\text { evidência e } \\
\text { reconhecer } \\
\text { subjetividades. }\end{array}$ & $\begin{array}{c}\text { Reunir coisas } \\
\text { e produzir o } \\
\text { novo, nova } \\
\text { solução; } \\
\text { generalização, } \\
\text { planificação e } \\
\text { produção; } \\
\text { proposição de } \\
\text { alternativas. }\end{array}$ \\
\hline
\end{tabular}

Fonte: Roque Ascenção e Valadão (2017, p. 15), com base em Anderson e Krathwohl (2001).

Em outra frente, Jo e Bednarz (2009), ao assumirem o pensamento espacial como operação que envolve conceitos espaciais, ferramentas de representação e modos de raciocínio (NRC, 2006), buscam desenvolver os níveis de complexidade envolvidos na construção na produção de operações de raciocínio. Tais níveis - de entrada, processamento e saida - que envolvem diferenciadas habilidades e competências de raciocínio, são sistematizadas por Duarte (2016, p. 183-184).

Segundo os autores, Jo e Bednarz (2009) constroem a taxonomia dos modos de raciocínio com base em trabalhos situados no campo da Neurociência e da Psicologia 
Cognitiva, que põem em perspectiva a aprendizagem como resultado das operações de entrada (quando são acionadas competências direcionadas a resgatar conhecimentos prévios, vivências, experiências e saberes do senso comum, ou mesmo outras informações da memória mais sistematizadas), de processamento (quando as informações capitalizadas no momento da entrada são tensionadas sob o crivo da análise, comparação, classificação e explicação, que exigem do aluno uma capacidade mais complexa de sistematizar e organizar ideias) e saída (quando o aluno será capaz de produzir e criar novas informações, conhecimentos e práticas, seja a partir da sistematização de informações presentes nos dois níveis anteriores, seja a partir do juízo crítico a respeito delas) - Tabela 01 .

Tabela 01: Modos de raciocínio, de acordo com Jo e Bednarz (2009)

\begin{tabular}{ccc}
\hline ENTRADA & PROCESSAMENTO & SAÍDA \\
\hline Nomear & Explicar & Avaliar \\
Definir & Analisar & Julgar \\
Listar & Estabelecer a causalidade & Prever \\
Identificar & Comparar & Prognosticar \\
Reconhecer & Contrastar & Hipotetizar \\
Recitar & Distinguir & Especular \\
Recordar & Classificar & Planejar \\
Observar & Categorizar & Criar \\
Descrever & Organizar & Projetar \\
Selecionar & Resumir & Inventar \\
Completar & Sintetizar & Imaginar \\
Contar & Inferir & Generalizar \\
Corresponder & Fazer analogias & Construir um modelo \\
& Exemplificar & Aplicar um princípio
\end{tabular}

Tradução e Organização: Duarte (2016, p. 184).

Isto posto, o que nos interessa, em termos dessa discussão, se realiza no diálogo que pode ser construído entre os autores, no sentido de que as operações de saída previstas em Jo e Bednarz (2009) podem estar situadas no campo da apropriação na taxonomia revisada de Bloom (Anderson e Krathwohl, 2001). Este diálogo nos permite avançar sobre temas e conteúdos geográficos encontrados na BNCC, e refletir sobre a disposição e construção conceitual das temáticas físico-naturais propostas nesse texto curricular. 


\section{Análise documental - materiais e procedimentos}

O material empírico utilizado na presente pesquisa consiste no documento que compõe a Base Nacional Comum Curricular, referente às orientações curriculares dos anos finais do ensino fundamental, cujo texto foi discutido e organizado desde 2015, e concluído em 2017. A versão final apresentada a sociedade civil dispõe das unidades temáticas, objetos de conhecimento e habilidades distribuídas por disciplinas e ciclos presentes na educação infantil e no ensino fundamental, enfatizando a preocupação em assegurar aos alunos um "percurso contínuo de aprendizagens entre as duas fases do Ensino Fundamental” (BRASIL, 2018).

Nesse movimento, à medida que assumimos como um de nossos recortes um direcionamento para as temáticas físico-naturais na Geografia, buscamos afinar um olhar para os momentos curriculares da disciplina geográfica em que tais temáticas aparecem no Ensino Fundamental. Tradicionalmente, este momentos correspondem, em termos de seriação, ao $6^{\circ}$ ano, princípio que a BNCC aparentemente não contrapôs. Mas verificamos, durante nossas análises da BNCC, habilidades que envolvem conteúdos da Geografia Física presentes no sétimo, oitavo e nono anos do Ensino Fundamental e, em vista disso, tais habilidades também serão alvos da discussão presente neste trabalho.

Isto posto, buscamos sintetizar, por meio dos itens a seguir, a forma como as habilidades de pensamento (Anderson e Krathwohl, 2000) e modos de raciocínio (Jo e Bednarz, 2009) estão sendo propostos à luz dos níveis de complexidade conceitual que caracteriza as temáticas físico-naturais nas séries finais do ensino fundamental. Interligados às habilidades previstas na $\mathrm{BNCC}$, os conceitos espaciais ligados às temáticas físico-naturais e seus níveis de complexidade, com base em Jo e Bednarz (2009) e descritos em Duarte (2016, p. 182-183), são organizados em:

- Primitivos: características espaciais básicas e fundamentais do/no espaço: localização, magnitude, identidade específica de um local

- Simples: conceitos estabelecidos a partir de conjuntos de primitivos espaciais. Distância; direção; conexão e ligação; movimento; transição; limite; região; formato; quadro de referência; arranjo; disposição; organização.

- Complexos: derivados da combinação de conjuntos de conceitos espaciais simples. A combinação de primitivos espaciais com conceitos espaciais simples produzem conceitos espaciais mais complexos e abstratos. Distribuição; padrão; dispersão e aglomeração; densidade; difusão; dominância; rede e hierarquia; associação espacial; sobreposição; camada; gradiente; perfil; relevo; escala; projeção cartográfica.

Valendo-se da relação entre as habilidades de pensamento (Anderson e Krathwohl, 2000), os modos de raciocínio (Jo e Bednarz, 2009) e os níveis de complexidade dos conceitos espaciais (Jo e Bednarz, 2009), os quadros 02, 03, 04, 05, 06, 07, 08 e 09 demonstram uma síntese interpretativa acerca das temáticas físiconaturais nos anos finais do Ensino Fundamental, segundo a BNCC (BRASIL, 2017). 


\section{$>$ Sexto ano}

Quadro 02: Sistematização de habilidades de pensamento e modos de raciocínio $-6^{\circ}$ ano.

\begin{tabular}{|c|c|c|c|c|}
\hline \multicolumn{5}{|c|}{ Modos de raciocínio, habilidades de pensamento e suas ocorrências na BNCC } \\
\hline $\begin{array}{c}\text { Modos de Raciocínio } \\
\text { (Jo e Bednarz, } \\
\text { 2009) }\end{array}$ & $\begin{array}{l}\text { Taxonomia Revisada de } \\
\text { Bloom (Anderson e } \\
\text { Krathwohl, 2000) }\end{array}$ & $\begin{array}{l}\text { Habilidades } \\
\text { (BNCC, } \\
2017,6^{\circ} \\
\text { ano) }\end{array}$ & Ocorrências & $\begin{array}{c}\text { Unidades } \\
\text { Temáticas } \\
\text { (BNCC, } \\
\text { 2017) }\end{array}$ \\
\hline \multirow{4}{*}{ ENTRADA } & \multirow{4}{*}{ RECORDAR } & Descrever & 2 & B \\
\hline & & Identificar & 2 & $\mathrm{C}, \mathrm{E}$ \\
\hline & & Reconhecer & 1 & B \\
\hline & & Localizar & 1 & $\mathrm{~B}$ \\
\hline \multirow{5}{*}{ PROCESSAMENTO } & \multirow{5}{*}{$\begin{array}{c}\text { COMPREENDER; } \\
\text { APLICAR; ANALISAR }\end{array}$} & Comparar & 2 & A,B \\
\hline & & Analisar & 3 & A,E \\
\hline & & Relacionar & 1 & B \\
\hline & & Explicar & 2 & $\mathrm{C}, \mathrm{D}$ \\
\hline & & Medir & 1 & $\mathrm{D}$ \\
\hline SAÍDA & AVALIAR; CRIAR & Elaborar & 1 & $\mathrm{D}$ \\
\hline
\end{tabular}

UNIDADES TEMÁTICAS: A) O sujeito e o seu lugar no mundo; B) Conexões e escalas; C) Mundo do trabalho; D) Formas de representação espacial; E) Natureza, ambientes e qualidade de vida. Organizado pelos autores, 2019.

Quadro 03: Sistematização de habilidades de pensamento e modos de raciocínio $-6^{\circ}$ ano.

\begin{tabular}{|c|l|}
\hline \multicolumn{2}{|c|}{ Complexidade dos conceitos espaciais físico-naturais } \\
\hline $\begin{array}{c}\text { Níveis de complexidade } \\
\text { (Jo e Bednarz, 2009) }\end{array}$ & \multicolumn{1}{|c|}{ Conceitos e complexidade espacial (BNCC, 2017) } \\
\hline PRIMITIVOS & Atmosfera/planeta; Formação vegetal \\
\hline SIMPLES & $\begin{array}{l}\text { Escoamento superficial; Movimentos do planeta; Solos/usos do } \\
\text { solo; Recurso hídrico; Padrão Climático }\end{array}$ \\
\hline COMPLEXOS & $\begin{array}{l}\text { Ciclo da água; Relevo; Bacia/rede hidrográfica; Escala; Dinâmica } \\
\text { climática }\end{array}$ \\
\hline
\end{tabular}

Organizado pelos autores, 2019. 


\section{$>$ Sétimo ano}

Quadro 04: Sistematização de habilidades de pensamento e modos de raciocínio $-7^{\circ}$ ano.

\begin{tabular}{|c|c|c|c|c|}
\hline \multicolumn{5}{|c|}{ Modos de raciocínio, habilidades de pensamento e suas ocorrências na BNCC } \\
\hline $\begin{array}{l}\text { Modos de Raciocínio } \\
\text { (Jo e Bednarz, 2009) }\end{array}$ & $\begin{array}{c}\text { Taxonomia } \\
\text { Revisada de } \\
\text { Bloom } \\
\text { (Anderson e } \\
\text { Krathwohl, } \\
\text { 2000) }\end{array}$ & $\begin{array}{l}\text { Habilidade } \\
\text { s (BNCC, } \\
2017,7^{\circ} \\
\text { ano) }\end{array}$ & Ocorrências & $\begin{array}{c}\text { Unidades } \\
\text { Temáticas } \\
\text { (BNCC, } \\
\text { 2017) }\end{array}$ \\
\hline ENTRADA & RECORDAR & - & - & - \\
\hline \multirow{3}{*}{ PROCESSAMENTO } & \multirow{3}{*}{$\begin{array}{l}\text { COMPREENDE } \\
\text { R; APLICAR; } \\
\text { ANALISAR }\end{array}$} & Discutir & 1 & $\mathrm{C}$ \\
\hline & & Comparar & 1 & $\mathrm{E}$ \\
\hline & & Caracterizar & 1 & $\mathrm{E}$ \\
\hline SAÍDA & $\begin{array}{l}\text { AVALIAR; } \\
\text { CRIAR }\end{array}$ & Avaliar & 1 & A \\
\hline
\end{tabular}

UNIDADES TEMÁTICAS: A) O sujeito e o seu lugar no mundo; B) Conexões e escalas; C) Mundo do trabalho; D) Formas de representação espacial; E) Natureza, ambientes e qualidade de vida. Organizado pelos autores, 2019.

Quadro 05: Sistematização de habilidades de pensamento e modos de raciocínio $-7^{\circ}$ ano.

\begin{tabular}{|c|l|}
\hline \multicolumn{2}{|c|}{ Complexidade dos conceitos espaciais físico-naturais } \\
\hline $\begin{array}{c}\text { Níveis de complexidade (Jo e } \\
\text { Bednarz, 2009) }\end{array}$ & $\begin{array}{c}\text { Conceitos e complexidade espacial (BNCC, } \\
\text { 2017) }\end{array}$ \\
\hline PRIMITIVOS & - \\
\hline SIMPLES & $\begin{array}{l}\text { Paisagem; Biodiversidade; Componentes físico- } \\
\text { naturais }\end{array}$ \\
\hline COMPLEXOS & Unidades de conservação \\
\hline
\end{tabular}

Organizado pelos autores, 2019. 


\section{$>$ Oitavo ano}

Quadro 06: Sistematização de habilidades de pensamento e modos de raciocínio $-8^{\circ}$ ano.

\begin{tabular}{|c|c|c|c|c|}
\hline \multicolumn{5}{|c|}{ Modos de raciocínio, habilidades de pensamento e suas ocorrências na BNCC } \\
\hline $\begin{array}{r}\text { Modos de Raciocínio } \\
\text { (Jo e Bednarz, 2009) }\end{array}$ & $\begin{array}{l}\text { Taxonomia Revisada } \\
\text { de Bloom (Anderson e } \\
\text { Krathwohl, 2000) }\end{array}$ & $\begin{array}{l}\text { Habilidades } \\
\text { (BNCC, } \\
2017,8^{\circ} \text { ano) }\end{array}$ & Ocorrências & $\begin{array}{c}\text { Unidades } \\
\text { Temáticas } \\
\text { (BNCC, } \\
\text { 2017) }\end{array}$ \\
\hline ENTRADA & RECORDAR & Identificar & 2 & E \\
\hline \multirow{2}{*}{ PROCESSAMENTO } & \multirow{2}{*}{$\begin{array}{c}\text { COMPREENDER; } \\
\text { APLICAR; } \\
\text { ANALISAR }\end{array}$} & Analisar & 3 & $\mathrm{C}, \mathrm{E}$ \\
\hline & & Discutir & 2 & $\mathrm{~A}, \mathrm{E}$ \\
\hline SAÍDA & AVALIAR; CRIAR & - & - & - \\
\hline
\end{tabular}

UNIDADES TEMÁTICAS: A) O sujeito e o seu lugar no mundo; B) Conexões e escalas; C) Mundo do trabalho; D) Formas de representação espacial; E) Natureza, ambientes e qualidade de vida. Organizado pelos autores, 2019.

Quadro 07: Sistematização de habilidades de pensamento e modos de raciocínio $-8^{\circ}$ ano.

\begin{tabular}{|c|c|}
\hline \multicolumn{2}{|c|}{ Complexidade dos conceitos espaciais físico-naturais } \\
\hline $\begin{array}{l}\text { Níveis de complexidade (Jo e Bednarz, } \\
\text { 2009) }\end{array}$ & $\begin{array}{c}\text { Conceitos e complexidade espacial } \\
\text { (BNCC, 2017) }\end{array}$ \\
\hline \multicolumn{2}{|l|}{ PRIMITIVOS } \\
\hline SIMPLES & $\begin{array}{l}\text { Condicionantes físico-naturais; Recursos } \\
\text { naturais; Recursos hídricos }\end{array}$ \\
\hline COMPLEXOS & Geomorfologia; Biogeografia; Climatologia \\
\hline
\end{tabular}

Organizado pelos autores (2019). 
$>$ Nono ano

Quadro 08: Sistematização de habilidades de pensamento e modos de raciocínio - $9^{\circ}$ ano.

\begin{tabular}{|c|c|c|c|c|}
\hline \multicolumn{5}{|c|}{ Modos de raciocínio, habilidades de pensamento e suas ocorrências na BNCC } \\
\hline $\begin{array}{c}\text { Modos de Raciocínio } \\
\text { (Jo e Bednarz, } \\
\text { 2009) }\end{array}$ & $\begin{array}{c}\text { Taxonomia } \\
\text { Revisada de } \\
\text { Bloom (Anderson } \\
\text { e Krathwohl, } \\
\text { 2000) }\end{array}$ & \begin{tabular}{|} 
Habilidades \\
(BNCC, \\
$2017,9^{\circ}$ \\
ano)
\end{tabular} & Ocorrências & $\begin{array}{c}\text { Unidades } \\
\text { Temátic } \\
\text { as } \\
\text { (BNCC, } \\
\text { 2017) }\end{array}$ \\
\hline ENTRADA & RECORDAR & - & - & - \\
\hline \multirow{3}{*}{ PROCESSAMENTO } & \multirow{3}{*}{$\begin{array}{c}\text { COMPREENDER; } \\
\text { APLICAR; } \\
\text { ANALISAR }\end{array}$} & Explicar & 1 & $\mathrm{E}$ \\
\hline & & Discutir & 1 & $\mathrm{~B}$ \\
\hline & & Analisar & 2 & $\mathrm{~B}$ \\
\hline SAÍDA & $\begin{array}{c}\text { AVALIAR; } \\
\text { CRIAR }\end{array}$ & - & - & - \\
\hline
\end{tabular}

UNIDADES TEMÁTICAS: A) O sujeito e o seu lugar no mundo; B) Conexões e escalas; C) Mundo do trabalho; D) Formas de representação espacial; E) Natureza, ambientes e qualidade de vida. Organizado pelos autores, 2019.

Quadro 09: Sistematização de habilidades de pensamento e modos de raciocínio - $9^{\circ}$ ano.

\begin{tabular}{|c|l|}
\hline \multicolumn{2}{|c|}{ Complexidade dos conceitos espaciais físico-naturais } \\
\hline $\begin{array}{c}\text { Níveis de complexidade (Jo e } \\
\text { Bednarz, 2009) }\end{array}$ & $\begin{array}{c}\text { Conceitos e complexidade espacial (BNCC, } \\
\text { 2017) }\end{array}$ \\
\hline PRIMITIVOS & Ambiente físico-naturais \\
\hline SIMPLES & $\begin{array}{l}\text { Componente físico-naturais; características } \\
\text { físico-naturais }\end{array}$ \\
\hline COMPLEXOS & \\
\hline
\end{tabular}

Organizado pelos autores (2019).

A habilidade discutir é originalmente encontrada na taxonomia de Bloom (1956) e não aparece na revisão proposta por Anderson e Krathwohl (2000). No entanto, entendemos que seu sentido é preservado como uma habilidade que prevê esclarecer, compreender ou interpretar informações com base no uso e elaboração de 
conhecimentos prévios, acionados por habilidades do momento de entrada (Jo e Bednarz, 2009). Na atual revisão, este sentido pode ser expresso, então, pelas habilidades de compreensão e aplicação.

A habilidade caracterizar, prevista no $7^{\circ}$ ano (EF07GE11), não faz parte das taxonomias consultadas para a pesquisa. Porém, sua definição incorpora diferentes competências cognitivas, desde a identificação até a generalização. Dessa forma, consideramos que o processo cognitivo de caracterizar reúne habilidades cognitivas dos três níveis de modos do raciocínio previstos por Jo e Bednarz (2009). Isto posto, abordamos esta habilidade em vista das competências por ela acionadas por meio de sua associação com os níveis de complexidade conceitual presentes no texto - dinâmica dos componentes físico-naturais, distribuição e biodiversidade - para afirmar que caracterizar, nesse contexto, significa uma habilidade que exige um nível complexo de cognição, situado, a nosso ver, no campo de processamento.

Nosso levantamento permitiu perceber a ocorrência de habilidades de pensamento e modo de raciocínio, compreendendo suas variabilidades. Os quadros 1, 3, 5 e 7 indicam a prevalência de habilidades de processamento (analisar, comparar, explicar, relacionar, medir, discutir), em detrimento das de entrada e saída. Isto quer dizer que as habilidades em torno das temáticas físico-naturais reforçam procedimentos, modos e habilidades de raciocínio que operam em nível procedimental complexo e de apropriação (ANDERSON e KRATHWOHL, 2001). De forma não menos importante, limitam as habilidades de pensamento que possibilitem ao aluno o alcance do conhecimento sistematizado e autônomo.

A exemplo disso, verifica-se a inabilidade da $\mathrm{BNCC}$ em reivindicar a observação como habilidade primária de produção do pensamento espacial, especialmente no sexto ano, momento cognitivo ligado às dimensões vernaculares (CLAVAL, 2010) de produção de conhecimento geográfico.

Nas séries finais do ensino fundamental, fases da aprendizagem onde espera-se que a complexidade conceitual e cognitiva envolva o estímulo de habilidades mais autônomas - como a criação, o planejamento e a hipótese -, percebemos o predomínio de habilidades que privilegiam o processamento. Os quadros do $8^{\circ}$ e $9^{\circ}$ ano revelaram, por exemplo, que modos de raciocínio de saída não se fazem presentes nem para as temáticas físico-naturais, tampouco para as temáticas voltadas para a sociedade (urbana, econômica ou cartográficas), o que chamou a atenção, do que possa se pensar de antemão. $\mathrm{O}$ documento de forma geral não apresenta habilidades de pensamento que envolvam ações diretas para que o aluno possa desenvolver algo novo ou realizar tarefas criativas. É este limite da superfície textual do documento que lhe caracteriza como base orientadora, abrindo espaços para que as redes de ensino possam desdobrar ou incentivar seus educadores a buscarem possíveis desdobramentos para as habilidades de referência, aumentando as possibilidades de estímulos ao raciocínio geográfico.

O texto de introdução da BNCC para os anos finais do ensino fundamental considera o "espaço biográfico" como espaço vivido e o tempo vivido a serem levados 
em conta como ponto de partida e finalidade de suas unidades temáticas e habilidades. Destaca também a necessidade de desenvolver habilidades voltadas para o uso de diferentes linguagens. A noção de temporalidade, espacialidade e diversidade são abordadas de forma mais complexa e deve levar em conta a perspectiva dos direitos humanos. No que considera como contribuição da Geografia para a educação básica, o desenvolvimento do pensamento espacial implica um raciocínio geográfico como interpretação e representação de leituras de mundo.

Para tanto, é necessário assegurar a apropriação de conceitos para o conhecimento factual (com destaque para os acontecimentos que podem ser observados e localizados no tempo e no espaço) e para o exercício da cidadania. (BRASIL, 2017, pág. 358).

Da associação entre os processos cognitivos, os conceitos geográficos e a situação geográfica como elementos-chave para o estudo dos objetos de aprendizagem (BRASIL, 2017, p. 359), a resolução de problemas apresenta-se como possibilidade didática que compreende, por um lado, os aspectos fundamentais da realidade, mediados pelos princípios da espacialidade dos fenômenos - tempo, espaço e escala (ROQUE ASCENÇÃO e VALADÃO, 2017), e os princípios do raciocínio geográfico: analogia, conexão, diferenciação, extensão, localização e ordem (BRASIL, 2017, p. 358).

Ao estudarmos as unidades temáticas, objetos de conhecimento e habilidades descritas para o ensino fundamental, nos deparamos com o reforço de conceitos espaciais complexos interrelacionados a modos de raciocínio de entrada e processamento, desconsiderando a previsão da observação, habilidade primária da Geografia. Este preceito sinaliza uma questão importante, que diz respeito ao fato de que as temáticas físico-naturais na Geografia Escolar envolvem, sobretudo, situações de aprendizagem que demandam abstrações derivadas da necessidade inicial de observação, que, por sua vez, se desdobra em outras habilidades, como selecionar, reconhecer, experienciar e descrever, quase todas situadas no campo de entrada dos modos de raciocínio.

Nesse sentido, o que significa descrever o ciclo da água (habilidade EF06GE04 da BNCC), no nível de complexidade exigido, para um aluno do sexto ano? Ou se partimos do pressuposto em que o pensamento espacial é a forma pelo qual a Geografia interpreta a espacialidade dos fenômenos, tencionamos a proposta das unidades temáticas, no qual o pensamento espacial está diretamente condicionado aos conteúdos, conceitos e habilidades restritos à cartografia.

Duarte (2016) apresenta em sua tese os elementos primordiais do pensamento espacial, como já salientado anteriormente, e considera as representações cartográficas como uma das ferramentas de representação, não a totalidade. Uma vez que o raciocínio geográfico é “ [...] uma forma de pensar autônoma de estruturar o pensamento, uma forma original de pensar" (GOMES, 2017, p. 21), ele parte primordialmente da ação cognitiva de observar, só então desdobrando-se hibridamente em outros princípios, que são mais explorados pela BNCC. Entretanto, consideramos que a debilidade da BNCC 
encontra-se na continuidade da construção conceitual das temáticas físico-naturais mediadas por habilidades e modos de raciocínio que operam nos campos da entrada e do processamento (Jo e Bednarz, 2009), privilegiando a apreensão de conceitos não observáveis em relação ao imediato concreto (ciclo da água, bacia hidrográfica, relevo). Observando isso, defendemos, ao resgatarmos a ideia de situação geográfica, a mediação possível entre a habilidade da observação e a construção de conceitos cotidianos (tempo meteorológico, vegetação, morro, rio), de modo que seja possível construir a complexificação conceitual para níveis os níveis de processamento e saída (Jo e Bednarz, 2009) tomando relações e práticas cotidianas como pontos de partida.

$\mathrm{O}$ que gostaríamos de ressaltar é o destaque dado pela própria BNCC para a situação geográfica como "[...] o procedimento para o estudo dos objetos de aprendizagem pelos alunos. " (BRASIL, 2017, pág. 363). A situação geográfica pode ser compreendida como um método que, segundo Silveira (1999, p. 22), é "um veículo de uma ou de algumas das possibilidades existentes no mundo, na formação socioespacial, na região que se depositam, isto é, se geografizam no lugar".

A nosso ver, a situação geográfica, por estar articulada à primazia da observação e dos níveis cognitivos de entrada resgatados a partir do sítio geográfico, pode ser vista como potência para a produção do conhecimento e complexidade conceitual no campo das temáticas físico-naturais, se consideradas suas peculiaridades pedagógicas. Esta perspectiva é uma forma de tratamento dos conteúdos da Geografia escolar, e aproximam-se dos questionamentos primordiais da Geografia, elencados por Cavalcanti (2012) - onde? por que? como? por que nesse lugar e não em outro?. Dessa forma, consideramos que os princípios do raciocínio geográfico apresentados na BNCC (BRASIL, 2017, p. 358) - analogia, conexão, diferenciação, distribuição, extensão, localização e ordem - encontram-se em articulação com a formulação dos questionamentos primordiais da Geografia, se considerarmos as habilidades ligadas às temáticas físico-naturais. Corroborando da ideia de espacialização do fenômeno defendida por Roque Ascenção e Valadão (2017), acrescentamos que tal articulação pode oferecer a possibilidade de desenvolver uma leitura escalar que nos ajude a pensar, enquanto professores, a mediação entre a situação geográfica (observação e cotidiano) e a construção de conceitos complexos, no tocante ao tratamento pedagógico das temáticas físico-naturais.

\section{Conclusão}

A implementação da Base Nacional Comum Curricular, como era esperado, abriu muitas frentes para discussões em torno da complexidade curricular da educação básica em diversas vertentes, desde o debate de conteúdos disciplinares até as implicações de um currículo nacional. Neste cenário, nossa motivação em estudar e refletir acerca das mudanças e permanências curriculares na Geografia escolar foi motivada a partir das discussões em torno do raciocínio geográfico que tem permeado as pesquisas na área. Acompanhando tais discussões em textos acadêmicos, eventos e disciplinas de pós-graduação, percebemos a necessidade de estudar e compartilhar as 
questões que se se fizeram presentes ao longo do período de implementação da base até sua finalização no ano de 2018, com a apresentação do texto para o ensino médio.

A análise das habilidades e objetos de conhecimento da BNCC possibilitaram uma leitura cuidadosa do documento, para que fosse possível entender, em termos de conceitos e conteúdos, quais as diferenças entre os Parâmetros Curriculares Nacionais e o atual currículo nacional. Consideramos que as diferenças nas temáticas físico-naturais não são ostensivas, posto que nossa análise constatou que conteúdos e conceitos foram aglutinados em habilidades e objetos de conhecimento para articularem-se à complexidade da nova proposta de um documento "mais enxuto". No entanto, o atual documento, ao propor uma perspectiva voltada aos princípios básicos do raciocínio geográfico, limita textualmente o pensamento espacial à unidade que trata dos conteúdos de cartografia. E diante de nossa pesquisa, tal aspecto reforçou que a proposta da BNCC para as temáticas físico-naturais, ao mobilizar modos de raciocínio e habilidades de pensamento, privilegia níveis de entrada e processamento no campo das operações de raciocínio, bem como a exploração de conceitos espaciais complexos.

Verificamos, também, a necessidade de resgatar a observação como habilidade primária de produção do conhecimento geográfico ao longo dos anos finais do ensino fundamental, de modo a resgatar a ideia de situação geográfica na direção da produção de sentidos significativos para as temáticas físico-naturais em múltiplas realidades escolares. Para além disso, destacamos que ações voltadas para a criação (nível de saída) poderiam incluir habilidades de pensamento como planejar, elaborar, produzir...

Por fim, ressaltamos a importância da situação geográfica como orientação teórica e metodológica que articula os princípios geográficos e as habilidades de pensamento, valorizando ainda mais a Geografia como uma forma primordial de pensamento.

\section{Referências Bibliográficas}

ANDERSON, Lorin W.; KRATHWOHL, David R. (Ed.) A Taxonomy for Learning, Teaching, and Assessing: a revision of Bloom's Taxonomy of Educational Objectives. Boston: Allyn e Bacon, Pearson Education Group, 2001.

BLOOM, Benjamin. S. (Ed.) et al. Taxonomy of educational objectives: The classification of educational goals. Handbook I: Cognitive domain. London: Longmans, 1956.

BRASIL. Ministério da Educação. Base Nacional Comum Curricular. Brasília: MEC, 2018.

CAVALCANTI, Lana de Souza. O ensino de Geografia na escola. Campinas: Papirus, 2012

CLAVAL, Paul. Terra dos homens: a Geografia. São Paulo: Contexto, 2010. 
DUARTE, Ronaldo Goulart. Educação Geográfica, Cartografia Escolar e Pensamento Espacial no segundo segmento do Ensino Fundamental. 2016. 310p. Tese (Doutorado em Geografia). Faculdade de Filosofia e Ciências Humanas, Universidade de São Paulo, São Paulo, 2016.

GERSMEHL, Philip J.; GERSMEHL, Carol B. Spatial Thinking by Young Children: Neurologic Evidence for Early Development and "Educability". Journal of Geography. 106: p. 181-191, 2007.

GOMES, Paulo Cesar da Costa. Quadros geográficos: uma forma de ver, uma forma de pensar. Rio de Janeiro: Bertrand Brasil, 2017.

JO, Injeong; BEDNARZ, Sarah. Evaluating geography textbook questions from a spatial perspective: Using concepts of space, tools of representation, and cognitive processes to evaluate spatiality. Journal of Geography 108: p. 4-13, 2009. Disponível em: http://dx.doi.org/10.1080/00221340902758401.

LACLAU, Ernesto. Emancipação e Diferença. Rio de Janeiro: EdUERJ, 2011.

LOPES. Alice Casimiro; MACEDO, Elizabeth. Teorias de currículo. São Paulo: Cortez, 2011.

MACEDO, Elizabeth. Base Nacional Curricular Comum: A falsa oposição entre conhecimento para fazer algo e conhecimento em si. Educação em Revista. Belo Horizonte; v.32; |n.02; p. 45-67. Abril-Junho, 2016.

NATIONAL RESEARCH COUNCIL. Learning to think spatially: GIS as a support system in the K-12 curriculum. Washington: National Research Council Press, 2006. ISBN: 0-309-53191-8, 332 p. Disponível em http://www.nap.edu/catalog/11019.html (Acesso em 03/08/2018).

ROQUE ASCENÇÃO, Valéria de Oliveira; VALADÃO, Roberto Célio. Complexidade conceitual na construção do conhecimento do conteúdo por professores de geografia. Revista Brasileira de Educação em Geografia, Campinas, v. 7, n. 14, p. 5-23, jul./dez., 2017.

SILVEIRA, Maria Laura. Uma situação geográfica: do método à metodologia. Revista TERRITÓRIO, ano IV, n.6, p. 21-28. jan./jun. 1999.

SHULMAN, Lee S. Those who understand: knowledge growth in teaching. Educational Researcher. v.15, n,2, p.4-14, feb. 1986.

Agradecimentos: O presente trabalho foi realizado com apoio da Coordenação de Aperfeiçoamento de Pessoal de Nível Superior - Brasil (CAPES) - Código de Financiamento 001. Agradecemos o apoio financeiro e institucional FAPESP com a bolsa registrada sob o número de processo omitido para avaliação. 


\section{Anniele Freitas}

Doutoranda em Geografia pela Universidade Estadual de Campinas, mestra em Geografia e graduada em Licenciatura em Geografia pela Universidade Federal do Rio de Janeiro.

Rua Carlos Gomes, 250 CEP: 13083-855 - Campinas, SP.

E-mail: anniesfreitas@gmail.com

\section{Thiago Manhães Cabral}

Doutorando em Geografia pela Universidade Estadual de Campinas e graduado em Licenciatura em Geografia pela Universidade Federal Fluminense.

Rua Carlos Gomes, 250 CEP: 13083-855 - Campinas, SP.

E-mail: thiagomanhaescabral@gmail.com

Recebido para publicação em fevereiro de 2019 Aprovado para publicação em outubro de 2019 